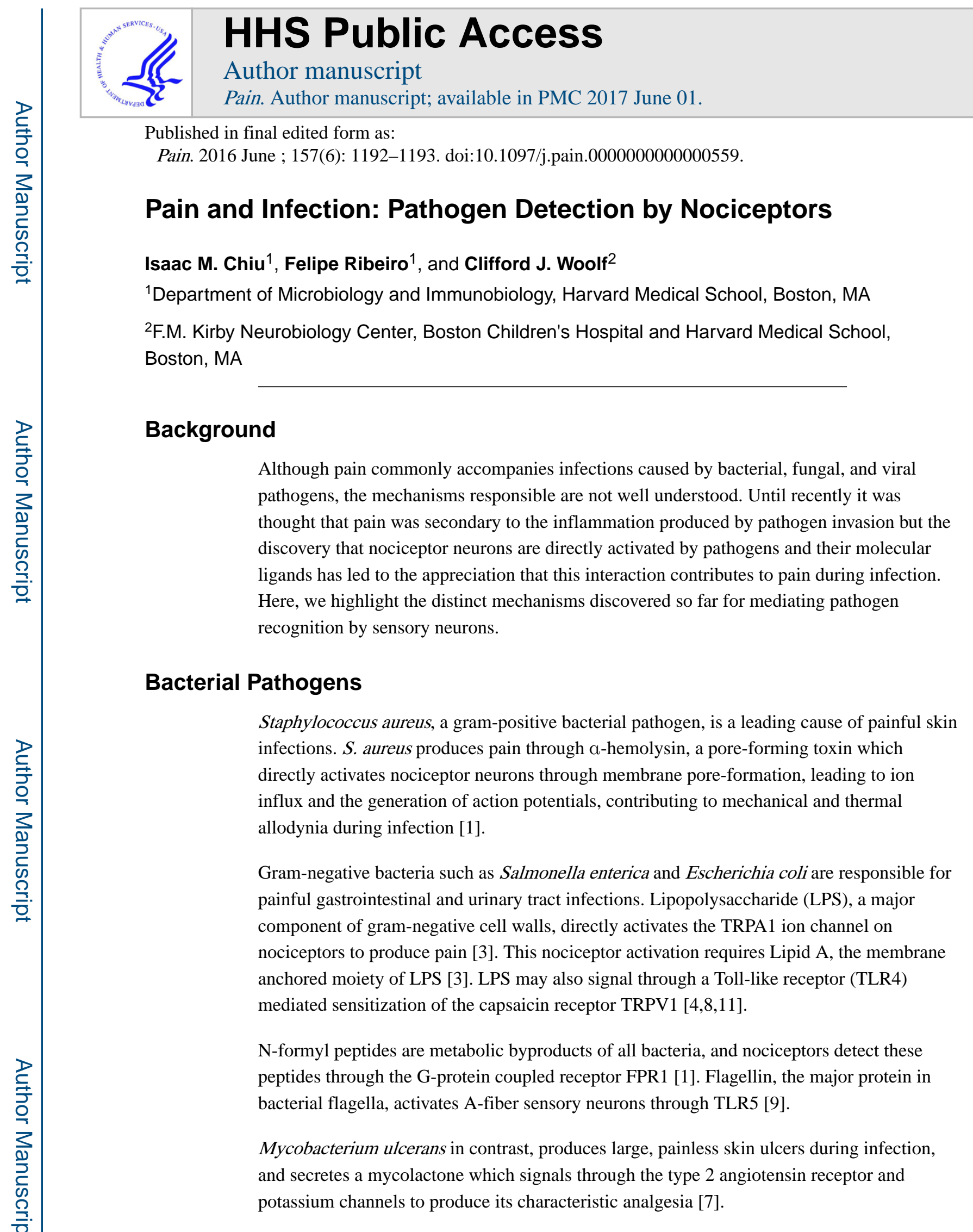




\section{Viral and Fungal Pathogens}

Viral pathogens also produce pain during infection, such as the common viral sore throat, but the mechanisms of nociceptor activation/sensitization produced by these pathogens are less well understood. TLR3 and TLR7, which recognize double-stranded and singlestranded RNA, respectively, are expressed by pruriceptor neurons and contribute to chronic itch [2,5], but whether they generate sensory disturbances in response to viral infection is not yet known.

HSV-1, HSV-2, and VZV infect nociceptor neurons to produce a variety of painful syndromes including cold sores and shingles [10]. However, it is unknown whether specific intracellular or extracellular viral recognition mechanisms by the sensory neurons mediate this pain.

The fungal pathogen Candida albicans and its cell wall component zymosan directly induce calcium influx into nociceptors [6] and this may contribute to the pain of thrush.

Interestingly, nociceptors mediate a protective skin immune response against $C$. albicans [6].

\section{Pain and infection: Beneficial for the Host or Pathogen?}

Pain in response to pathogen invasion may serve its usual essential defense against danger role by warning the host of the presence of pathogenic invasion. Conversely, pathogens may have evolved mechanisms to manipulate nociceptor activity, and the pain it causes, to facilitate spread from host-to-host or within infected tissues. Nociceptors release molecular mediators from their peripheral terminals, such as the neuropeptides CGRP and substance P, that have powerful effects on immune cell recruitment and activation during infection $[1,3,6]$. Further work is required to determine the beneficial or harmful nature of pain in host defense against specific types of pathogens, nevertheless as every physician knows, pain is a prominent early feature of most infections.

\section{References}

1. Chiu IM, Heesters BA, Ghasemlou N, Von Hehn CA, Zhao F, Tran J, Wainger B, Strominger A, Muralidharan S, Horswill AR, Bubeck Wardenburg J, Hwang SW, Carroll MC, Woolf CJ. Bacteria activate sensory neurons that modulate pain and inflammation. Nature. 2013; 501:52-57. doi: 10.1038/nature 12479. [PubMed: 23965627]

2. Diogenes A, Ferraz CC, Akopian AN, Henry MA, Hargreaves KM. LPS sensitizes TRPV1 via activation of TLR4 in trigeminal sensory neurons. J Dent Res. 2011; 90:759-764. doi: 10.1177/0022034511400225. [PubMed: 21393555]

3. Kashem SW, Riedl MS, Yao C, Honda CN, Vulchanova L, Kaplan DH. Nociceptive sensory fibers drive interleukin-23 production from CD301b+ dermal dendritic cells and drive protective cutaneous immunity. Immunity. 2013; 43:515-526. doi:10.1016/j.immuni.2015.08.016 (2015). Nature 501, 52-57, doi:10.1038/nature12479. [PubMed: 26377898]

4. Li Y, Adamek P, Zhang H, Tatsui CE, Rhines LD, Mrozkova P, Li Q, Kosturakis AK, Cassidy RM, Harrison DS, Cata JP, Sapire K, Zhang H, Kennamer-Chapman RM, Jawad AB, Ghetti A, Yan J, Palecek J, Dougherty PM. The Cancer Chemotherapeutic Paclitaxel Increases Human and Rodent Sensory Neuron Responses to TRPV1 by Activation of TLR4. J Neurosci. 2015; 35:13487-13500. doi:10.1523/JNEUROSCI.1956-15.2015. [PubMed: 26424893] 
5. Liu T, Berta T, Xu ZZ, Park CK, Zhang L, Lü N, Liu Q, Liu Y, Gao YJ, Liu YC, Ma Q, Dong X, Ji RR. TLR3 deficiency impairs spinal cord synaptic transmission, central sensitization, and pruritus in mice. J Clin Invest. 2012; 122:2195-2207. doi:10.1172/JCI45414. [PubMed: 22565312]

6. Liu T, Xu ZZ, Park CK, Berta T, Ji RR. Toll-like receptor 7 mediates pruritus. Nat Neurosci. 2010; 13:1460-1462. doi:10.1038/nn.2683. [PubMed: 21037581]

7. Marion E, Song OR, Christophe T, Babonneau J, Fenistein D, Eyer J, Letournel F, Henrion D, Clere N, Paille V, Guérineau NC, Saint André JP, Gersbach P, Altmann KH, Stinear TP, Comoglio Y, Sandoz G, Preisser L, Delneste Y, Yeramian E, Marsollier L, Brodin P. Mycobacterial toxin induces analgesia in buruli ulcer by targeting the angiotensin pathways. Cell. 2014; 157:1565-1576. doi: 10.1016/j.cell.2014.04.040. [PubMed: 24949969]

8. Meseguer V, Alpizar YA, Luis E, Tajada S, Denlinger B, Fajardo O, Manenschijn JA, FernándezPeña C, Talavera A, Kichko T, Navia B, Sánchez A, Señarís R, Reeh P, Pérez-García MT, LópezLópez JR, Voets T, Belmonte C, Talavera K, Viana F. TRPA1 channels mediate acute neurogenic inflammation and pain produced by bacterial endotoxins. Nat Commun. 2014; 5:3125. doi:10.1038/ ncomms4125. [PubMed: 24445575]

9. Min H, Lee H, Lim H, Jang YH, Chung SJ, Lee CJ, Lee SJ. TLR4 enhances histamine-mediated pruritus by potentiating TRPV1 activity. Mol Brain. 2014; 7:59. doi:10.1186/s13041-014-0059-9. [PubMed: 25139109]

10. Nagel MA, Gilden D. Neurological complications of varicella zoster virus reactivation. Curr Opin Neurol. 2014; 27:356-360. doi:10.1097/WCO.0000000000000092. [PubMed: 24792344]

11. Xu ZZ, Kim YH, Bang S, Zhang Y, Berta T1, Wang F, Oh SB, Ji RR. Inhibition of mechanical allodynia in neuropathic pain by TLR5-mediated A-fiber blockade. Nat Med. 2015; 21:13261331. doi:10.1038/nm.3978. [PubMed: 26479925] 


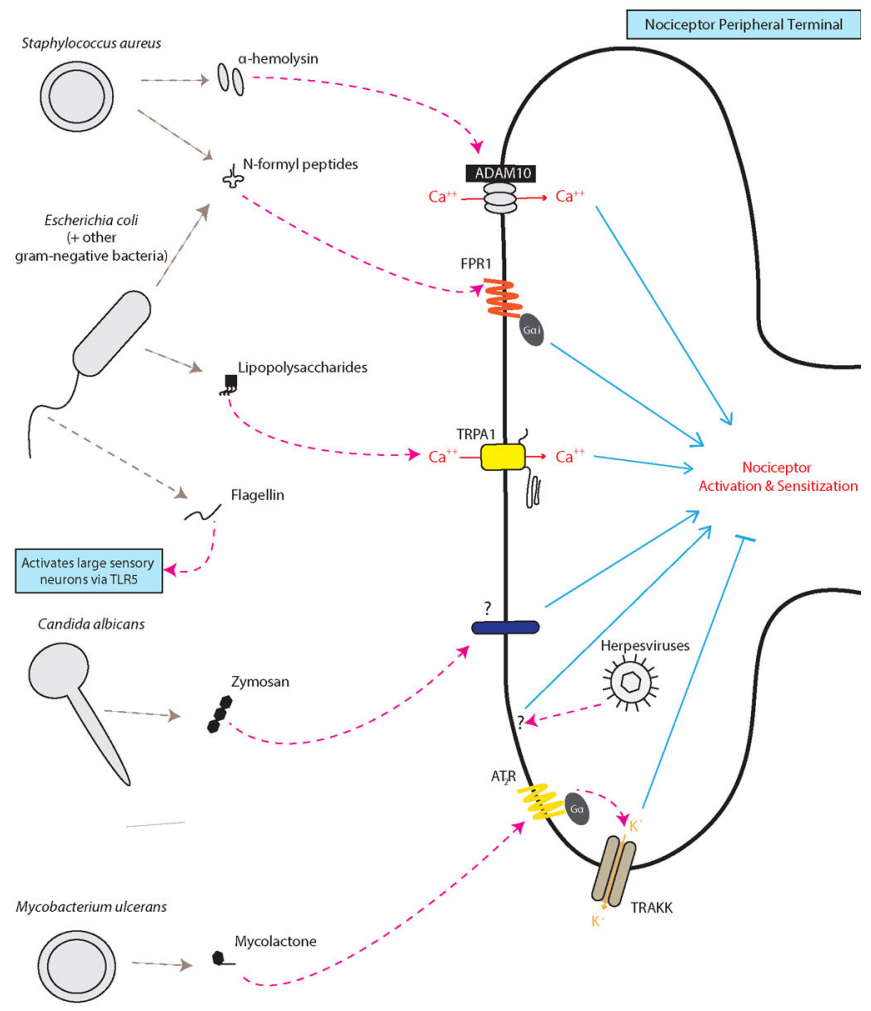

Figure 1. 